\title{
MBD-based Modeling and Dynamic Characteristic Analysis of Electric Vehicle Key Components and Hybrid Control Unit
}

\author{
Jaewoo Yoon ${ }^{1}$, Ming Lin ${ }^{1}$ and Byeongwoo Kim ${ }^{1, *}$ \\ ${ }^{1}$ Department of Electrical Engineering, University of Ulsan, Korea \\ 1jewos0127@gmail.com, ${ }^{1}$ flaaud159@naver.com,1*bywokim@ulsan.ac.kr
}

\begin{abstract}
In general, electric vehicles have significantly different structures compared to vehicles running on internal combustion engines owing to their use of electric motors as the source of power and batteries as energy-storage devices. Electric vehicles also demonstrate different driving performance and dynamic characteristics, as they are capable of recovering some of the energy wasted in the form frictional heat at the brake through use of regenerative braking during deceleration. The proposed study discusses a mathematical model constructed by identifying characteristics of certain key components and the hybrid control unit (HCU) of an electric vehicle. Corresponding correlations among these components were analyzed. In addition, a dynamic model of the electric vehicle was designed using the model-based design approach in accordance with the standard V-Model development process ISO 26262-an international standard for automotive safety. All models discussed herein were developed using the MATLAB/SIMULINK package, and dynamic characteristics of the vehicle were analyzed through simulations.
\end{abstract}

Keywords: Electric vehicles, model-based design (MBD) method, hybrid control unit

\section{Introduction}

Concerns over air-pollution levels and global warming have been on the rise in recent years owing to the overwhelming use of vehicles installed with internal combustion engines, which extract energy from the combustion of fossil fuels. As such, many countries in the world are making various efforts to reduce greenhouse gas (carbon dioxide, Freon, methane, etc.,) emissions [1]. In countries like South Korea, the United States, and Europe, various policies supporting insurance premiums, taxes, and subsidies are in effect to encourage consumers to opt for use of eco-friendly vehicles, instead of vehicles powered by internal combustion engines, when they buy a new car. Sale of vehicles running on internal combustion engines is expected be prohibited from the year 2025 onwards in Norway, 2030 onwards in the Netherlands, and 2040 onwards in UK and France. Unlike conventional vehicles powered by internal combustion engines, electric vehicles record almost zero carbon emissions while being driven owing to their use of electric motors and batteries as main power sources. Along with excellent energy efficiency, electric vehicles exhibit superior characteristics in terms of fuel economy and carbon dioxide reduction [2]. Further, many of the previous problems concerning lack of charging stations, long charging times, and short driving distance on a single charge have been addressed with recent advances in technology [3].

With electronic technology being applied to vehicles, the complexity of automotive electronic control systems is also increasing. In other words, the number of electronic components - microcontroller units (MCUs), sensors, and actuator-and their functions as well as the complexity of functions involved in such systems have undergone an

Received (October 21, 2017), Review Result (January 20, 2018), Accepted (January 25, 2018) 
exponential increase. Increasing complexity leads to higher system error possibilities, and such possibilities lead to vehicular defects, thereby resulting in accidents. Accidents caused by sudden unintended acceleration of Toyota's electric vehicle in 2009 may be considered as a representative case that illustrates the need for adoption safety measures against malfunctioning of and defects in automotive electronic control systems. This, in turn, causes problems, such as delay in development schedules and increase in cost of production owing to development of low-reliability products. To address such problems, ISO enacted ISO26262 - an international standard for automotive safety - to exercise legal control. ISO26262 comprises 10 parts and prescribes 43 requirements and recommendations. Both, hardware and software modules are developed in accordance with the development process of the V-Model that employs a model-based design (MBD) approach, thereby ensuring accurate design of a complicated system [4].

Since electric vehicles derive power from batteries, which are essentially energystorage devices and not fuels, the dynamic characteristics of power systems and vehicles employing conventional internal combustion engines must be analyzed based on electric vehicles, which requires accurate modeling and mathematical analysis of the entire system. Permanent magnet synchronous motors (PMSMs) are frequently used in electric vehicles on account of their higher efficiency and torque density compared to other motors [5]. In addition, electric vehicles demonstrate higher energy efficiencies compared to vehicles powered by internal combustion engines owing to the fact that they can recover and use some of the energy wasted as frictional heat at the brake through use of regenerative braking and batteries during deceleration [6].

In the proposed study, the motor, battery, and power transmission device were modeled mathematically. In addition, a hybrid control unit (HCU), which generates the necessary power-when the driver steps on the accelerator pedal-and applies adequate regenerative braking and frictional heat at the brake-when the driver steps on the brake pedal-was designed, and entire systems of electric vehicles were integrated. Furthermore, dynamic characteristics of electric vehicles were analyzed using the MATLAB/SIMULINK package.

\section{Modeling of the Key Components of Electric Vehicles}

Figure 1 depicts the typical structure of an electric vehicle illustrating the key components of the drive system. The electric system of the concerned vehicle comprises a battery - an energy storage device, PMSM - a power device, and an HCU. The HCU calculates and controls the torque required by the PMSM and brake system at the instant when the driver steps on the accelerator or brake pedal. The mechanical system comprises transmission, differential, and brake systems, which deliver the power supplied by PMSM to the wheels.

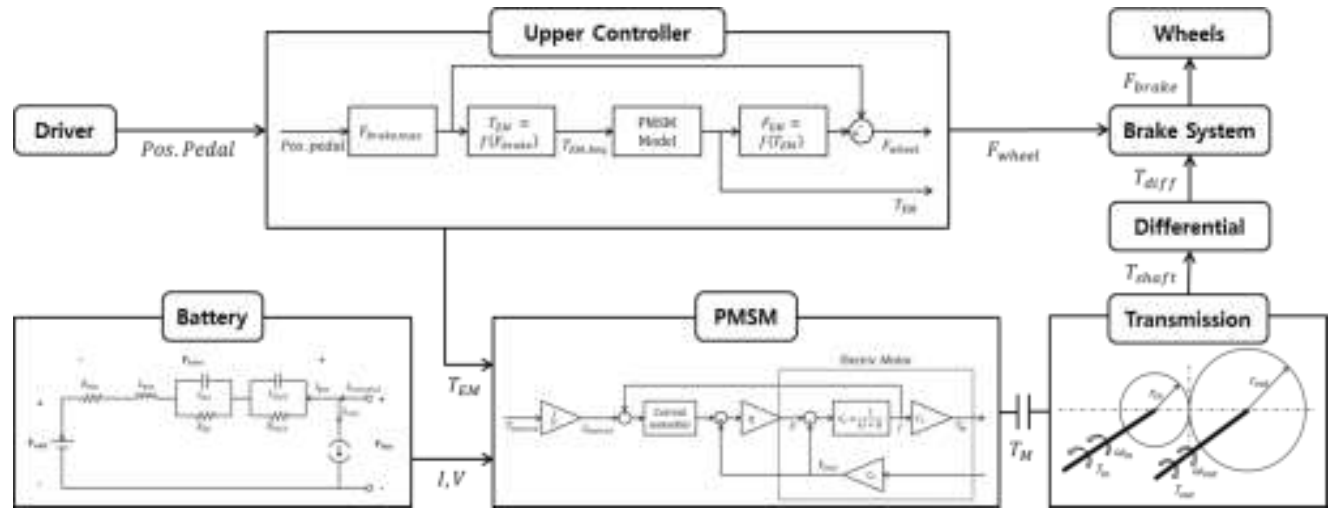

Figure 1. Overall Structure of an Electric Vehicle 


\subsection{Battery Modeling}

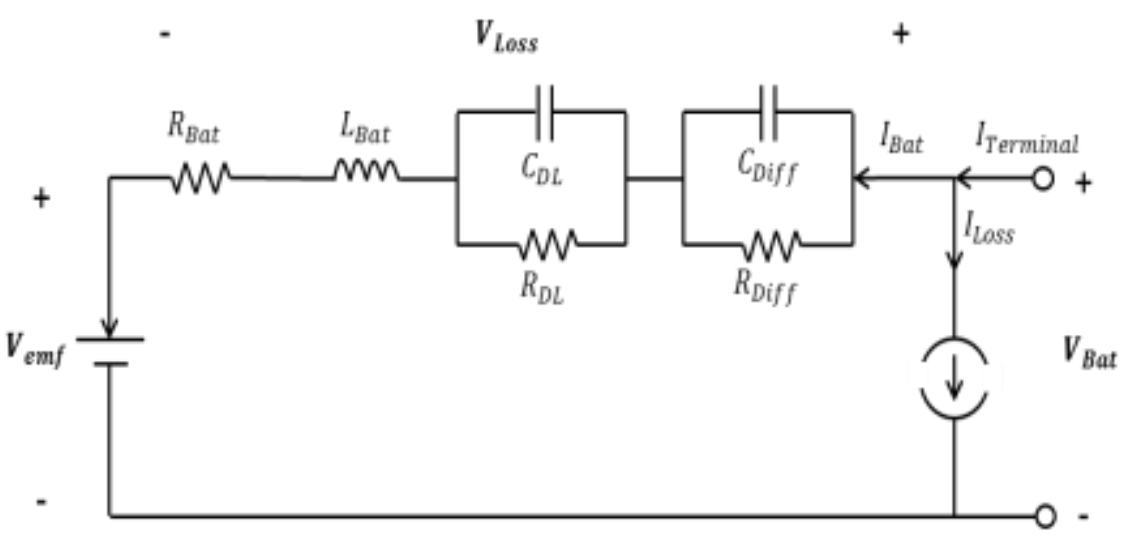

Figure 2. Battery Equivalent Circuit Model

Energy-storage devices (batteries) used in electric vehicles possess high energy densities and long service lives. The batteries of electric vehicles are used as packs, wherein several cells are combined. Batteries commonly used in the past utilized a simplified electrochemical model [7], [8]. It, however, could not reflect battery characteristics with strong nonlinearity [9-11]. Other battery models were, therefore, proposed using an equivalent circuit model, wherein resistances, capacitors, and voltage source from the circuit network were employed. In this study, battery cells based on the equivalent circuit model were modeled mathematically. A typical battery cell model is depicted in Figure 2 [12-14].

The cell voltage of a battery used in an electric vehicle is influenced by the double layer behavior, diffusion behavior, SoC of the battery, changes in internal resistance caused by temperature variations, and internal inductance of the battery. Such influences could be expressed in terms of the voltage lost $\left(V_{\text {Loss }}\right)$ within the battery. Thus, a terminal voltage model could be obtained by subtracting the $V_{\text {Loss }}$, which represents a lost portion of the electromotive force $\left(V_{e m f}\right)$ of the battery.

$$
V_{\text {Bat }}=V_{\text {emf }}-V_{\text {Loss }}
$$

Where,

$V_{\text {Bat }}$ : The battery terminal voltage.

$V_{\text {emf }}:$ The electromotive force voltage.

$V_{\text {Loss }}:$ The loss voltage.

The electromotive force of the battery could be obtained using the initial voltage of cells and the number of SoCs and cells constituting the battery pack.

$$
V_{\text {emf }}=n_{\text {cell }} V_{\text {cell }}(\mathrm{SoC})
$$

Where,

$n_{\text {cell }}:$ The number of battery cells.

$V_{\text {cell }}:$ The cell voltage.

SoC : The state of charge.

The voltage loss $\left(V_{\text {Loss }}\right)$ of the battery owing to double layer behavior, diffusion behavior, and temperature variations could be obtained as follows. 


$$
\begin{gathered}
V_{\text {Loss }}=\frac{1}{C_{D L}} \int\left(I_{\text {Bat }}-\frac{V_{C D L}}{R_{D L}}\right) d t+\frac{1}{C_{D i f f}} \int\left(I_{\text {Bat }}-\frac{V_{\text {CDiff }}}{R_{\text {Diff }}}\right) d t \\
+I_{\text {Bat }} R_{\text {Bat }}\left(\text { SoC }, I_{\text {Bat }}, T_{\text {Bat }}\right)+\frac{d I_{B a t}}{d t} L_{\text {Bat }}
\end{gathered}
$$

Where,

$I_{B a t}:$ The battery current.

$V_{D L}:$ The loss voltage double layer capacitance.

$C_{D L}$ : The double layer capacity.

$R_{D L}$ :The double layer resistance.

$V_{\text {Diff }}:$ The loss voltage diffusion capacitance.

$C_{\text {Diff }}:$ The diffusion capacitance.

$R_{\text {Diff }}:$ The diffusion resistance.

$T_{B a t}:$ The battery temperature.

$R_{B a t}:$ The battery resistance.

$L_{B a t}:$ The battery inductance.

Here, the SoC of the battery employed the Coulomb counting method [15]. The Coulomb counting method, represented by equation (4), helps in determining the current battery state by integrating the charging and discharging currents of the battery.

$$
\begin{gathered}
\text { SoC }=\operatorname{SoC}_{t=0} \frac{1}{C_{N}} \int\left(I_{\text {Terminal }}-I_{\text {Loss }}\right) d t \\
\left\{\begin{array}{c}
I_{\text {Bat }}-I_{\text {Loss }}>0: \text { charges the battery } \\
I_{\text {Bat }}-I_{\text {Loss }} \leq 0: \text { discharges the battery }
\end{array}\right.
\end{gathered}
$$

Where,

SoC : The state of charge.

So $C_{t=0}$ : The initial state of charge.

$C_{N}$ : The nominal capacity of battery.

$I_{\text {Terminal }}$ : The terminal current.

$I_{\text {Loss }}$ : The loss current.

\subsection{Modeling of PMSM and Torque Controller}

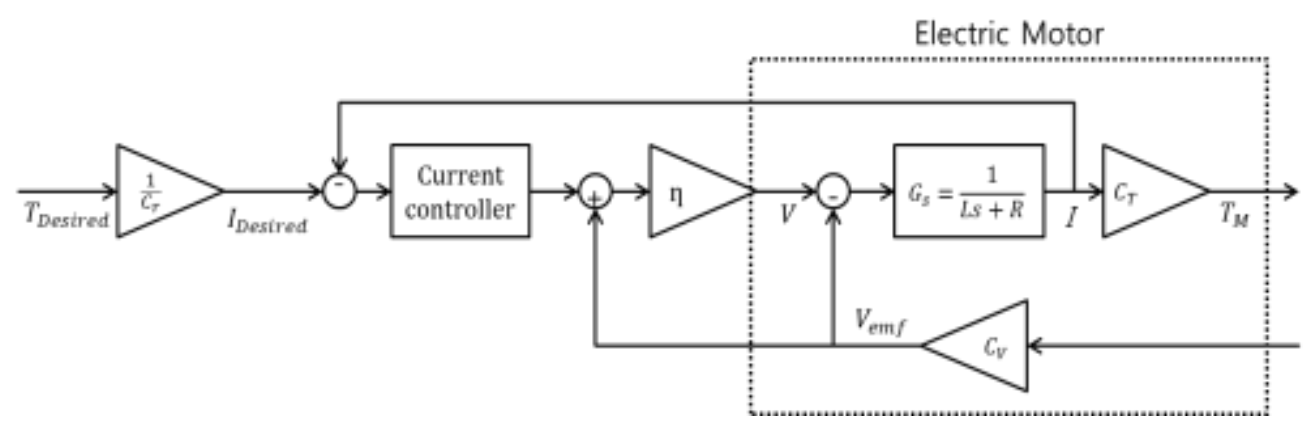

Figure 3. Modeling of PMSM and Torque Controller 
PMSMs are employed as power devices in various areas owing to their small size, high efficiency, and excellent control performance in terms of output power [16, 17]. PMSMs with high nonlinearity have been previously modeled mathematically, and various studies concerning PI controllers [18], robust controllers [19], sliding-mode control (SMC) [20, 21], and adaptive control [22] have been performed. In the proposed study, PMSM was modeled as a first-order system through use of a simple electromechanical equivalent circuit (equation 5). The machine-speed-depended back EMF voltage $V_{\text {emf }}$ is calculated with the machine voltage constant $C_{V}$. As depicted in Figure 3, the drive torque of PMSM was controlled by means of a PI current controller.

$$
G(s)=\frac{1}{L s+R}
$$

Where,

$R:$ The motor resistance.

$L$ : The motor inductance.

$C_{T}$ : The torque constant electric motor.

$C_{V}$ : The voltage constant electric motor.

$\eta$ :The efficiency power electronics.

\subsection{Drive-train Modeling}

Conventional vehicles powered by internal combustion engines require devices, such as flywheels and clutches, from the structural perspective. This is because their output is nonlinear and governed by the engine rpm. Electric vehicles, however, possess simple structures as they are capable of generating an approximately linear output over their entire operating range. As such, the transmission gear of the drive train employed in electric vehicle generally comprises only one or two stages.

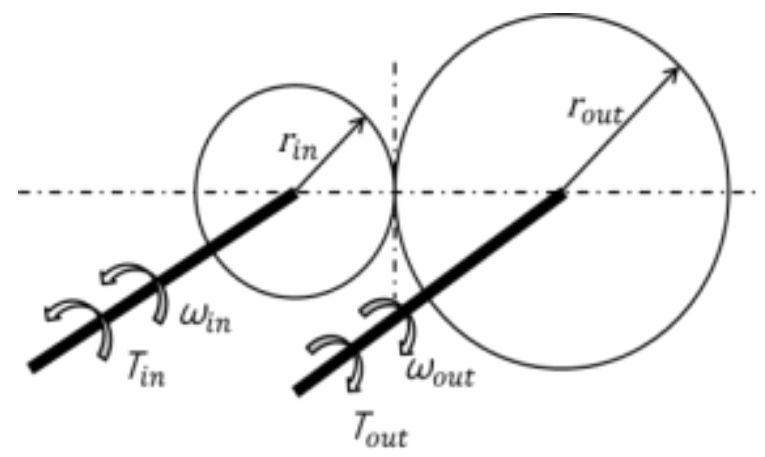

Figure 4. Transmission Gear Modeling

Gears are torque conversion devices. Gears in electric vehicles serve to deliver the torque generated by PMSM to each shaft and adjust the torque produced based on the gear ratio. Figure 4 depicts a simple schematic of the transmission gear model used in this study. The reduction gear ratio $(\lambda)$ can be defined as described in equation (6), and the rotational speed of the shaft could be defined as given in equation (7). $J_{\text {shaft }}, T_{\text {in }}, D$, and $T_{\text {out }}$, respectively represent the moment of inertia of the shaft, input torque, damping constant of the shaft, and output torque. 


$$
\begin{gathered}
\lambda=\frac{r_{\text {in }}}{r_{\text {out }}}=\frac{T_{\text {out }}}{T_{\text {in }}} \\
J_{\text {shaft }} \cdot w_{\text {shaft }}=\left(T_{\text {in }}-T_{\text {out }}\right)-D \cdot w
\end{gathered}
$$

\subsection{HCU Design}

Unlike conventional vehicles with internal combustion engines, electric vehicles employ the principle of regenerative braking described in previous sections [23-25]. Therefore, the HCU of an electric vehicle is required to not only control the torque necessary for vehicle acceleration but to also appropriately distribute the braking force at the brake and regenerative braking of PMSM during vehicle deceleration. The vehicle torque and brake controllers were designed in accordance with the pedal input provided by the driver.

2.4.1. Vehicle Torque Controller: Electric vehicles must be capable of performing accelerations and decelerations in accordance with the driver's accelerator- or brake-pedal input. The vehicle torque controller must, therefore, be able to calculate the torque required when the driver steps on the accelerator pedal. Likewise, it must be able to control PMSM by means of the regenerative braking torque calculated by the brake controller at the instant when the driver provide brake input. Torque required for vehicle acceleration uses map data measured in advance. PMSM torque, on the other hand, is calculated using the accelerator pedal value (\%) and rotational speed (rpm) of PMSM (Figure 5).

2.4.2. Brake Controller Design: The brake controller calculates the energy to be recovered from PMSM during regenerative braking and that to be consumed as frictional heat at the brake when the driver supplies brake input as depicted in Figure 6. It calculates the necessary braking force (Fbrake, max) in accordance with the amount of brake input provided by the driver. It also calculates the reverse torque (TEM) with due consideration of the gear ratio. The calculated reverse torque is transmitted to PMSM to perform regenerative braking. In addition, because regenerative braking alone cannot provide the required braking force, the brake controller was designed to supplement regenerative braking with the frictional force of the brake. Therefore, all the braking force applied is not lost in the form of frictional heat generated at the brake, and some of it is recovered by PMSM, thereby increasing the driving distance of electric vehicles.

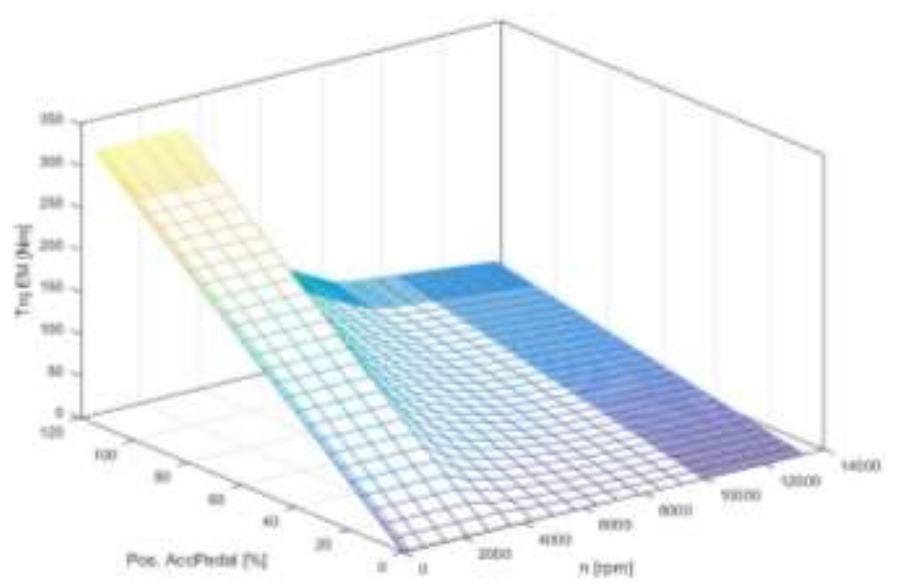

Figure 5. Accelerator Pedal - Motor Rotation Speed - Motor Torque Map 


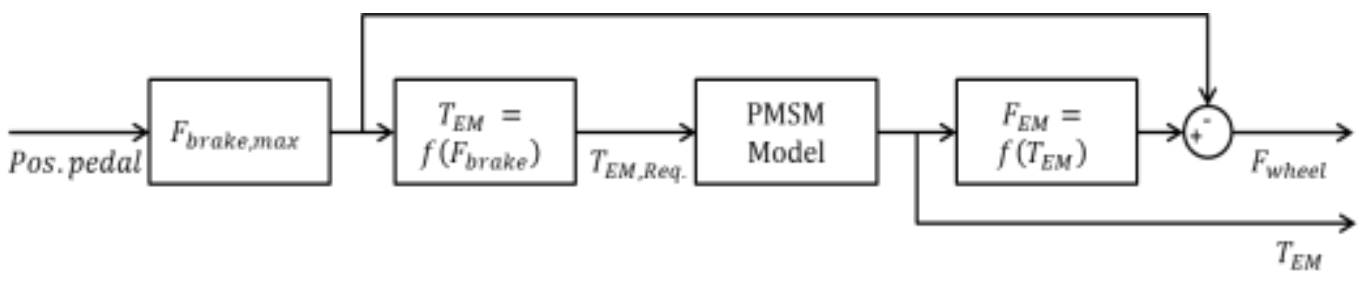

Figure 6. Configuration Drawing of Brake Controller

\section{Simulation Results and Discussion}

To verify the proposed mathematical model of the electric vehicle, parametric values for key components were set as depicted in Table 1. A 100-kW-class PMSM motor and an $11.1-\mathrm{kWh}$ battery were used, and the initial SoC was set at $80 \%$. dSAPCE's ASM Vehicle Dynamic was employed for the vehicle dynamics and drive models.

Table 1. Parameters of Key Components

\begin{tabular}{|l|l|l|}
\hline \multicolumn{1}{|c|}{ Parameter } & \multicolumn{1}{c|}{ Value } & \multicolumn{1}{c|}{ Unit } \\
\hline Efficiency, $\eta$ & 1 & - \\
\hline Inductance, $\mathrm{L}$ & 0.0018 & $\mathrm{H}$ \\
\hline Resistance, $\mathrm{R}$ & 0.862 & $\mathrm{Ohm}$ \\
\hline Voltage constant, $\mathrm{C}_{\mathrm{V}}$ & 0.0288 & $\mathrm{~V} / \mathrm{rpm}$ \\
\hline Torque constant, $\mathrm{C}_{\mathrm{T}}$ & 0.951 & $\mathrm{Nm} / \mathrm{A}$ \\
\hline Gear ratio, $\lambda$ & 3.2 & - \\
\hline Battery capacity & 11.1 & $\mathrm{Kwh}$ \\
\hline Vehicle Weight & 1880 & $\mathrm{~kg}$ \\
\hline
\end{tabular}

Simulation results demonstrate that the proposed electric vehicle could be driven for up to $3 \mathrm{~km}$ on a road at a maximum speed of $88 \mathrm{~km} / \mathrm{h}$. The accelerator and brake pedals were adjusted as depicted in Figures 7 and 8. When the electric vehicle first started, torque measuring approximately $285 \mathrm{Nm}$ was produced by PMSM. The maximum voltage applied to PMSM measured approximately $340 \mathrm{~V}$, and the corresponding current was of the order of $300 \mathrm{~A}$, thereby generating an output power of approximately $102 \mathrm{~kW}$ (Figures 11 and 12). During deceleration of the electric vehicle (i.e., when the driver stepped on the brake pedal), it was confirmed that reverse torque was applied and the battery was charged (Figure 10).

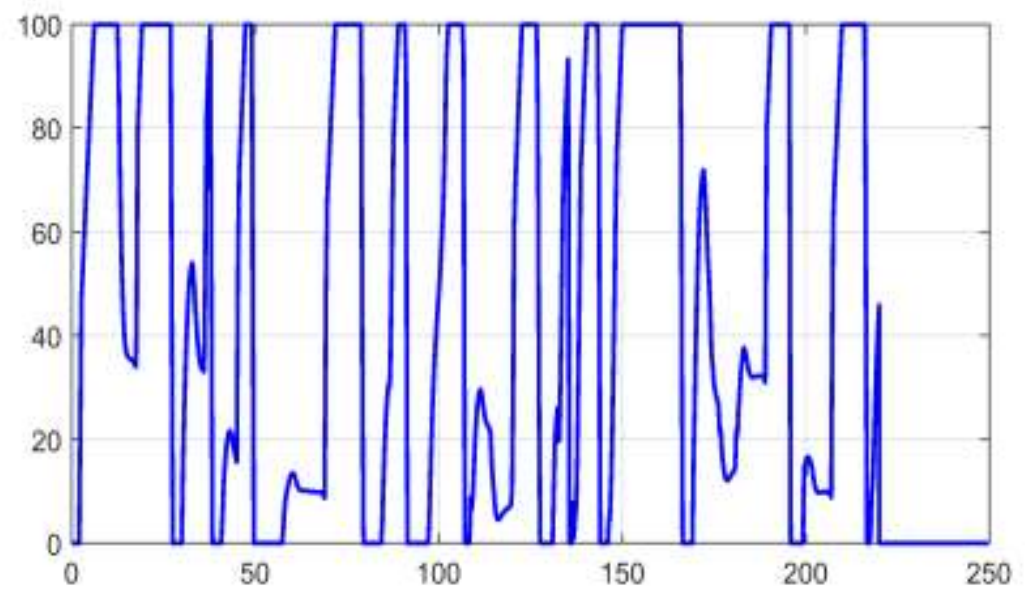

Figure 7. Pressed Amount of the Accelerator Pedal [\%] 


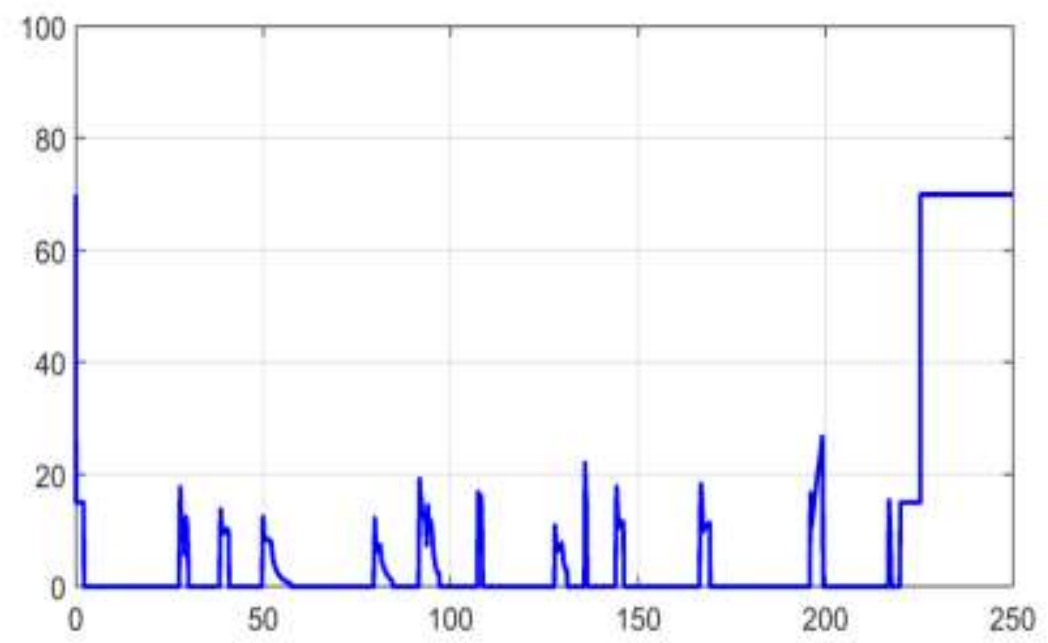

Figure 8. Pressed Amount of the Brake Pedal [\%]

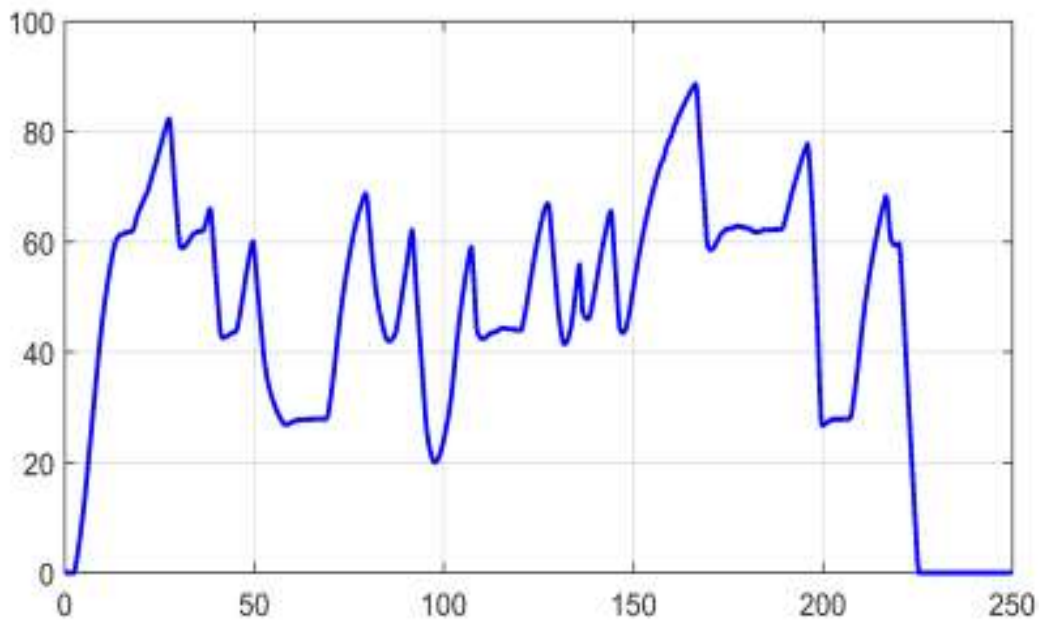

Figure 9. Driving Speed of the Vehicle $[\mathrm{km} / \mathrm{h}]$

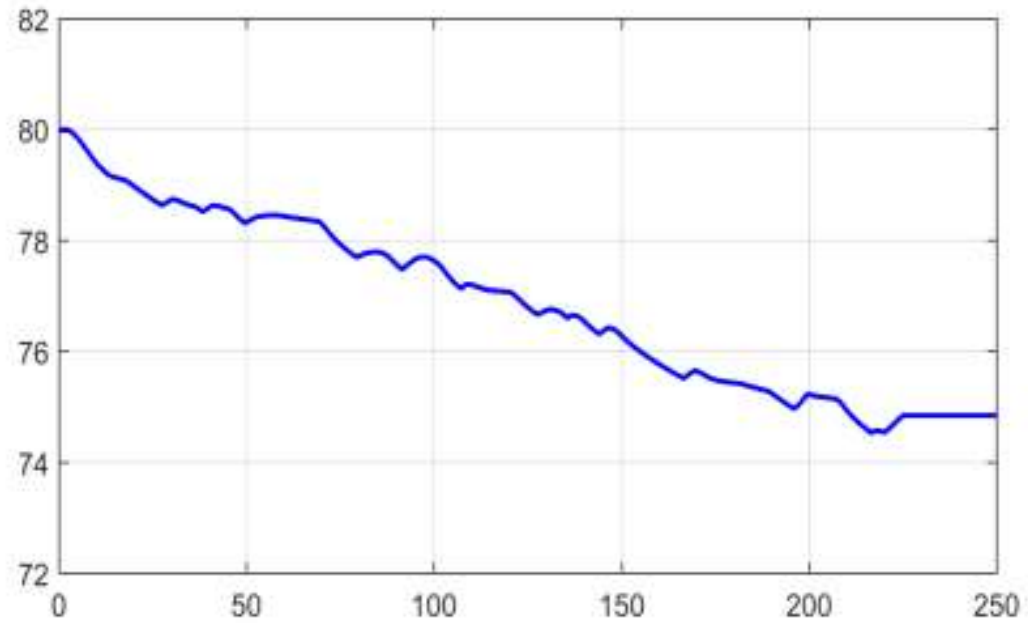

Figure 10. Battery SoC [\%] 


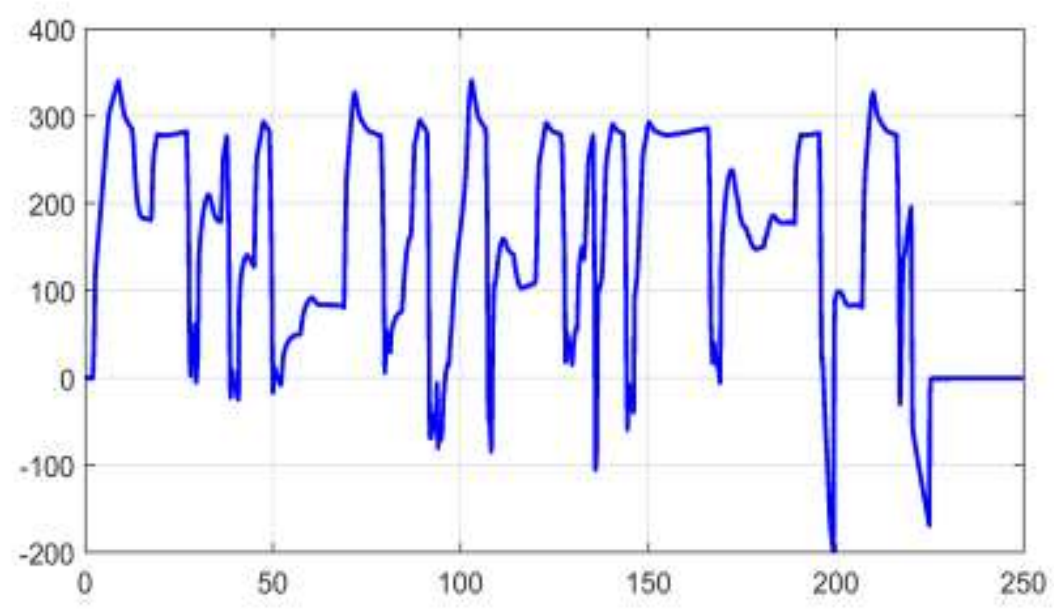

Figure 11. PMSM Voltage [V]

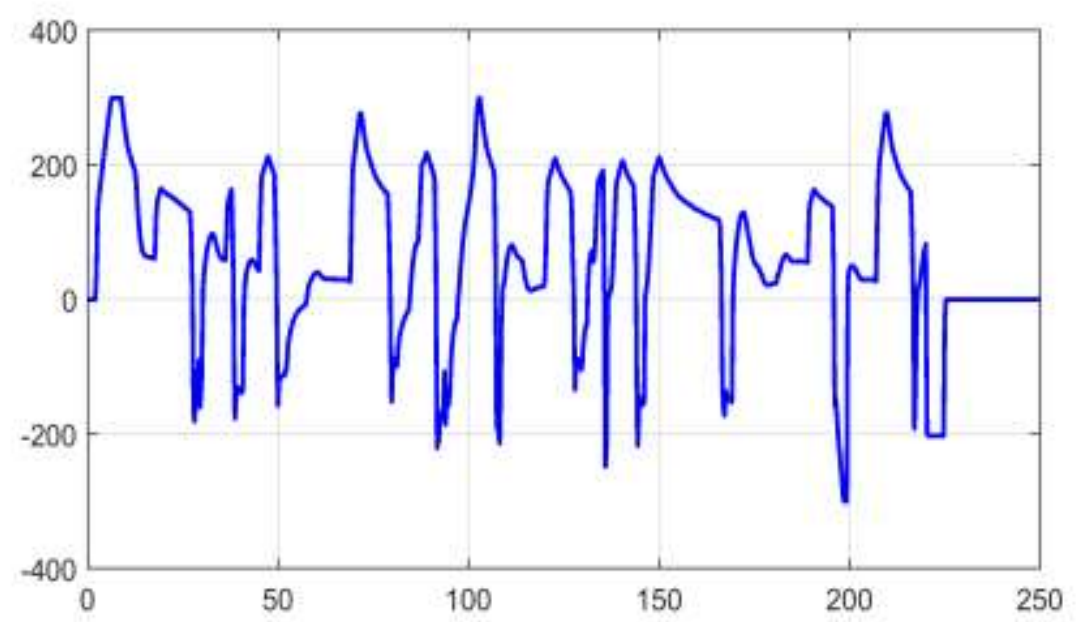

Figure 12. PMSM Current [A]

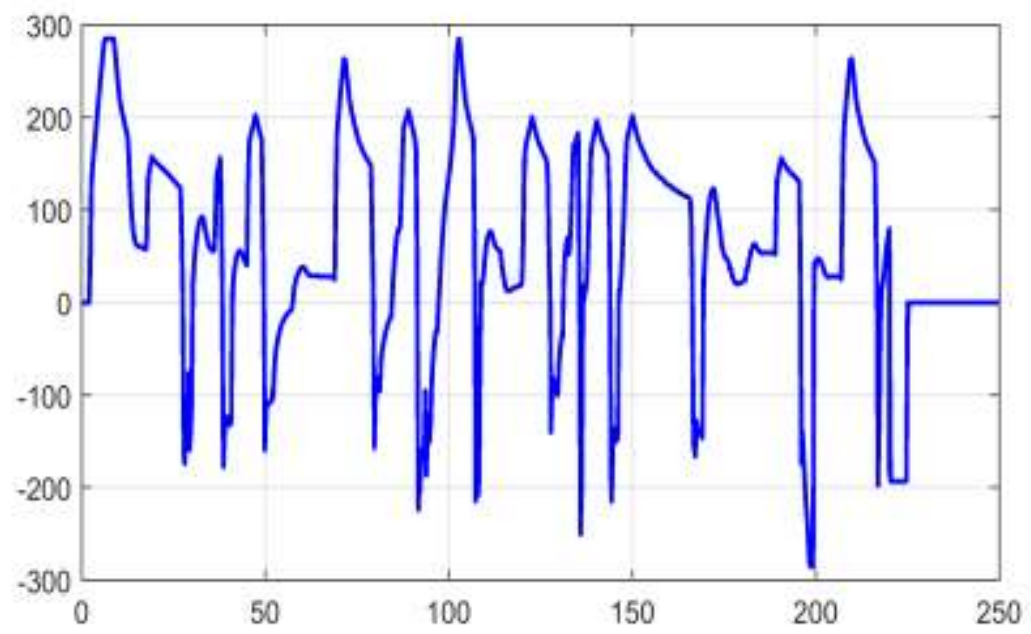

Figure 13. PMSM Torque [Nm] 


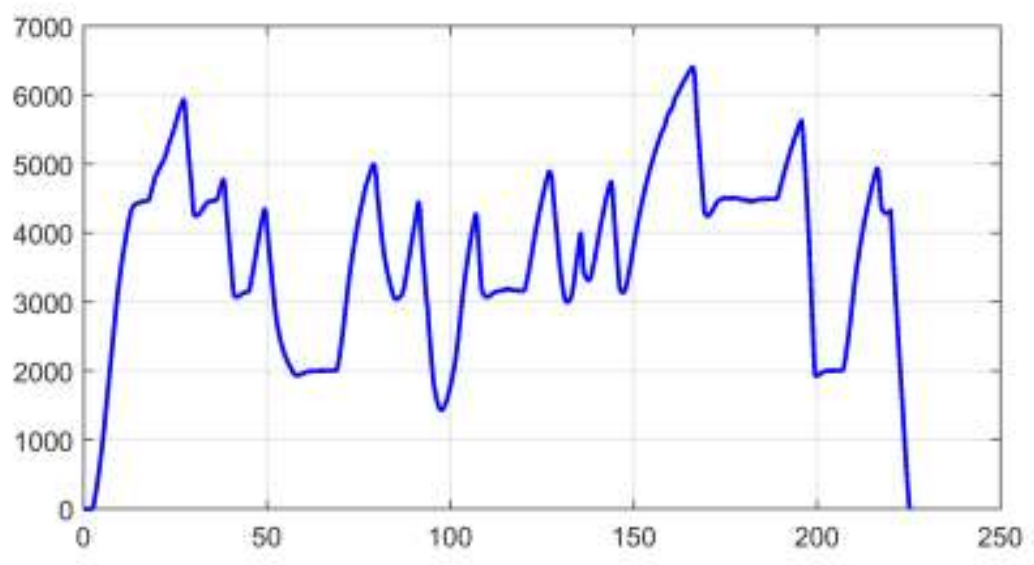

Figure 14. PMSM Shaft Speed [rpm]

\section{Conclusion}

The proposed study describes modeling and analysis of the characteristics of each key component of modern electric vehicles. The model of the electric vehicle, designed using the MBD approach, was verified via simulation, and the performance of the model was examined through analysis of data obtained from simulation results. In addition, it was confirmed that when a driver stepped on the brake pedal during vehicle deceleration, the regenerative braking system was set into operation and recovered some of the energy, which otherwise would have been consumed in the form of frictional heat at the brake. The status of the regenerative braking system operation could be confirmed by observing the increase in SOC level of the battery during deceleration. Although the entire system was constructed using a simplified model, the dynamic characteristics of electric vehicles could be investigated through torque and rpm ratings of the motor, current produced by the battery, and SOC changes in accordance with acceleration and/or brake inputs provided by a driver.

\section{Acknowledgments}

This paper is a revised and expanded version of a paper entitled "MBD-based Electric Vehicle Core Part Modeling and Dynamic Property Analysis" presented at "J. Yoon, M. Lin and B. Kim, International Journal of Engineering \& Technology for Automobile Security" and is supported by the Industry Core Technology Development Project "Development of $2 \mathrm{~kW} / \mathrm{kg}, 100 \mathrm{~kW}$ class IPMSM electric drive system with high efficiency cooling" through the Ministry of Trade, Industry and Energy (Grant Number : 10063006).

\section{References}

[1] W. H. Chung, J. E Kang, T. G. Kang and H. Yoon, "Cities and Green Economy: Comparative Study of Korea, China and Japan”, Korea Environment Institute, (2012).

[2] A. Holms and R. Argueta, "A Technical Research Report: The Electric Vehicle", (2010).

[3] M. Smith and J. Castellano, "Costs Associated With Non-Residential Electric Vehicle Supply Equipment: Factors to consider in the implementation of electric vehicle charging stations", no. DOE/EE-1289, (2015).

[4] N. K. Pandey, S. M. Vedula, S. Thimmalapura and K. Tellikepalli, "Novel Approach for Model-Based Development-Part II: Developing Virtual Environment and Its Application”, SAE Technical Paper, no. 2016-01-0322, (2016).

[5] B. Wu and B. Chen, "Study the Performance of Battery Models for Hybrid Electric Vehicles", IEEE/ASME 10th International Conference on Mechatronic and Embedded Systems and Applications (MESA), (2014) September 10-12. 
[6] K. Itani, A. D. Bernardinis and A. Jammal, "Energy Management of a Battery-Flywheel Storage System used for Regenerative Braking Recuperation of an Electric Vehicle", Industrial Electronics Society, IECON 42nd Annual Conference of the IEEE, (2016) October 23-26.

[7] D. Domenico, S. Anna and F. Giovanni, "Lithium-Ion Battery State of Charge and Critical Surface Charge Estimation Using an Electrochemical Model-Based Extended Kalman Filter", Journal of dynamic systems, measurement, and control, vol. 132, no. 6, (2010), 061302.

[8] B. Vijayasekaran and R. Venkat, "A quick and efficient method for consistent initialization of battery models", Electrochemistry Communications, vol. 9, no. 7, (2007), pp. 1772-1777.

[9] T. Marc, B. Oliver and U. S. Dirk, "Development of a voltage-behavior model for NiMH batteries using an impedance-based modeling concept", Journal of Power Sources, vol. 175, no. 1, (2008), pp. 635-643.

[10] S. Lee, J. Kim, J. Lee and B. H. Cho, "State-of-charge and capacity estimation of lithium-ion battery using a new open-circuit voltage versus state-of-charge", Journal of Power Sources, vol. 185, no. 2, (2008), pp. 1367-1373.

[11] R. Jackey, M. Saginaw, P. Sanghvi and J. Gazzarri, "Battery Model Parameter Estimation Using a Layered Technique: An Example Using a Lithium Iron Phosphate Cell”, SAE Technical Paper, no. 201301-1547, (2013).

[12] M. Chen and G. A. Rincon-Mora, "Accurate Electrical Battery Model Capable of Predicting Runtime and I-V Performance", IEEE transactions on energy conversion, vol. 21, no. 2, (2006), pp. 504-511.

[13] H. He, R. Xiong and J. Fan, "Evaluation of Lithium-Ion Battery Equivalent Circuit Models for State of Charge Estimation by an Experimental Approach", Energies, vol. 4, no. 4, (2011), pp. 582-598.

[14] R. M. S. Santos, C. L. G. d. S. Alves, E. C. T. Macedo, J. M. M. Villanueva and L. V. Hartmann, "Estimation of lithium-ion battery model parameters using experimental data", 2nd International Symposium on Instrumentation Systems, Circuits and Transducers (INSCIT), Fortaleza, (2017), August 28-September 1.

[15] S. Piller, M. Perrin and A. Jossen, "Methods for state-of-charge determination and their applications", Journal of power sources, vol. 96, no. 1, (2001), pp. 113-120.

[16] C. French and P. Acarnley, "Direct torque control of permanent magnet drives", IEEE Transactions on Industry Application, vol. 32, no. 5, (1996), pp. 1080-1088.

[17] L. Romeral, A. Fabrega, J. Cusido, A. Garcia and J. A. Ortega, "Torque ripple reduction in a PMSM driven by direct torque control”, 2008 IEEE Power Electronics Specialists Conference, Rhodes, (2008), pp. 4745-4751.

[18] Y. X. Su, C. H. Zheng and B. Y. Duan, "Automatic Disturbances Rejection Controller for Precise Motion Control of Permanent-Magnet Synchronous Motors", IEEE Transactions on Industrial Electronics, vol. 52, no. 3, (2005), pp. 814-823.

[19] G. Feng, Y. F. Liu and L. P. Huang, "A New Robust Algorithm to Improve the Dynamic Performance on the Speed Control of Induction Motor Drive", IEEE Transactions on Power Electronics, vol. 19, no. 6, (2004), pp. 1614-1627.

[20] M. A. Fnaiech, F. Betin, G. A. Capolino and F. Fnaiech, "Fuzzy Logic and Sliding-Mode Controls Applied to Six-Phase Induction Machine with Open Phases", IEEE Transactions on Industrial Electronics, vol. 57, no. 1, (2010), pp. 354-364.

[21] G. H. B. Foo and M. F. Rahman, "Direct Torque Control of an IPM-Synchronous Motor Drive at Very Low Speed Using a Sliding-Mode Stator Flux Observer", IEEE Transactions on Power Electronics, vol. 25, no. 4, (2010), pp. 933-942.

[22] H. H. Choi, N. T. T. Vu and J. W. Jung, "Digital implementation of an adaptive speed regulator for a pmsm", IEEE Transactions on Power Electronics, vol. 26, no. 1, (2011), pp. 3-8.

[23] X. Nian, F. Peng and H. Zhang, "Regenerative Braking System of Electric Vehicle Driven by Brushless DC Motor", IEEE Transactions on Industrial Electronics, vol. 61, no. 10, (2014), pp. 5798-5808.

[24] J. Ko, S. Ko, H. Son, B. Yoo, J. Cheon and H. Kim, "Development of Brake System and Regenerative Braking Cooperative Control Algorithm for Automatic-Transmission-Based Hybrid Electric Vehicles", IEEE Transactions on Vehicular Technology, vol. 64, no. 2, (2015), pp. 431-440.

[25] L. Li, X. Li, X. Wang, J. Song, K. He and C. Li, "Analysis of downshift's improvement to energy efficiency of an electric vehicle during regenerative braking”, Applied Energy, vol. 176, no. 15, (2016), pp. 125-137.

\section{Authors}

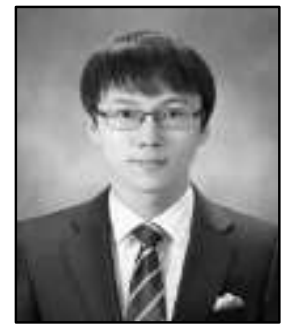

Jaewoo Yoon received the B.E degree in electrical engineering in University of Ulsan, Ulsan, South Korea. He is pursuing his M.E degree in electrical engineering in University of Ulsan, Ulsan, South Korea. His current research interests include advanced driving assistance system (ADAS), autonomous emergency braking (AEB) system, information fusion theories 
and application for vehicle localization, and design of intelligent vehicles.

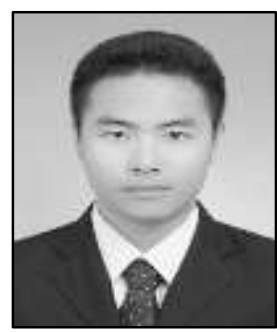

Ming Lin received the bachelor degree in Shanghai University of Engineering Science, Shang Hai, China. He is pursuing his master degree in electrical engineering in University of Ulsan, Ulsan, South Korea. His research interests include advanced driving assistance system (ADAS), and autonomous emergency braking (AEB) system.

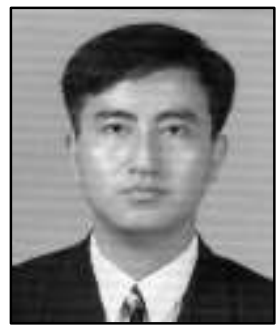

Byeongwoo Kim received the B.E, M.E. and Ph.D degree in Precision Mechanical Engineering from Hanyang University. He worked at KOSAKA Research Center in 1989. He worked at KATECH electrical technology Research Center from 1994 to 2006. Now he is a professor in the School of electrical engineering in University if Ulsan, Ulsan, South Korea from 2006. His current research interests include advanced driving assistance system (ADAS). 